\title{
ELEMENTS OF VISUAL IDENTIFICATION IN BRAND PRESENTATION
}

\author{
Lesia Mikhieieva \\ Department of Design Municipal \\ Higher education institution "Khortytsia National Educational and Rehabilitation Academy" \\ Zaporizhzhia Regional Council \\ 59 Naukove Mistechko str., Zaporizhzhia, Ukraine, 69017 \\ lesyamikhey@gmail.com
}

\section{Abstract}

The analysis of modern literary sources demonstrates that studying of visual identification elements is considered by authors of scientific researches in the aspect of their use for business-structures. Specific sectors of human activity and the art sphere are either ignored or not taken into account. But some art spheres have their own specific peculiarities that can add design theory by the new view on a series of classic definitions and paradigms.

The article considers visual identification elements in the classic design theory and additional visual identification elements on the example of a genre sphere of human activity in music art. The problem arose at describing visual identification elements of music groups that influence the formation of their brand. There are determined several visual identification elements, inherent to creative groups, working in the sphere of audiovisual art.

The tasks, set at the research:

- analysis of literary sources in the research problem;

- analysis of visual materials for revealing certain signs;

- determination of additional visual identification elements, inherent to creative groups, working in the sphere of audiovisual art;

- brief description of obtained results.

Research methods: review of literary data in the topic; collection of a sampling of designs objects; observation and comparison of design objects from the collected material.

Results: there are offered additional visual identification elements of the thematic activity spheres in music art.

Scientific novelty: an ordered list of visual identification elements, both common and additional, used for brand creation.

Practical importance: the offered list of graphic identification elements may be used in scientific studies; in the learning process at studying the research topic at preparing learning and methodical manuals in graphic design.
\end{abstract}

Keywords: visual identification, brand, music group, merch, corporative style, advertising, logotype.

DOI: $10.21303 / 2504-5571.2020 .001326$

\section{Introduction}

Visual identification in the Ukrainian sphere of design art last time acquires more expressive and clear structure for creating a brand, but just needs some concretization and definition in theory. Besides general defined identification elements, such as logotype, color, print in different application fields in business or art, these elements may be added also by other identification elements, no less important for a certain activity sphere. Modern researchers of this topic mainly study it by visual identification elements of business-structures, despite the specificity of other activity spheres. But if we study visual identification in a certain branch, we can observe manifestations of identification elements, not inherent to business-structures.

In his works Morgan G. considered visual identification as "a reflection of culture of an enterprise, its separate elements by artistic and graphic means, stylistic techniques, providing the formation of a united image of a firm in all directions of its activity" [1]. Considering firms, organizations and groups, working in different activity spheres, the researcher comes to the conclusion that visual (graphic) identification includes a share of identity that is perception of an object as an element from a certain category or market niche, and also a share of otherness that is visual separation of this object from identical ones. All this provides visual perception, integrates all visual elements and moments of psychological effect in a visual style, influences creation of a brand of a 
certain group, including music one. Barden $\mathrm{Ph}$. [2] and Berman M. [3] express a similar opinion in their works.

Neumeier M. wrote in his work about brand peculiarities and defines brand as "a sixth feeling of a client as to a product, service or company" [4, p. 31]. Ogilvy D. [5] and Norman D. [6] wrote about advertising work that influences the brand development, expressing an opinion that brand is not a logotype and not something that a company says about itself, but people say about it". In Ukraine visual identification as a phenomenon was studied also by such researchers as Bessonova L. [7], Polyak R. [8], and other. A Heller S., Chwast S. [9] studied it from the point of view of graphic styles and application in advertising.

The aim of this study is to improve the existent theory about the list of visual identification elements, taking into account the specificity of music art.

\section{Materials and methods}

Modern Ukrainian music groups with main brand characteristics are a material of the research. For that there was formed a list of 150 music groups, working in different music styles and having an own logotype. Chronologic frames of the research are formed by the period from 1991 to the present time. A research method is observation and comparison of design objects and also their branching by certain criteria.

\section{Results}

Today Ukrainian graphic design becomes very symbolic in its striving for creating visual identification elements of a brand, remarkable among others and easily recognized. Visual identification is today considered as a common effective way to present a commodity or service at the market. In its turn, brand as a phenomenon it is rather a complex of visual, verbal and nonverbal components, based on which an opinion about an object forms, and also an influence indicator of used visual identification elements.

Visual identification is a visual part of a complex of information about a product. Design theory contains commonly used visual identification elements, inherent to any design object that needs advertising. Such commonly used identification elements are logotype (symbol), firm set of colors, firm set of prints and also often used elements - corporative personage, sound, form, cloth elements and so on.

Briefly considering commonly used visual identification elements, we can say, that logotype is a print original inscription of a design object name, consists of linguistic symbols of different written language alphabets and/or other digital symbols or punctuation marks. According to new tendencies, signs and their combination with an inscription are also named by the word "logotype", but it doesn't change the essence of visualization and the function of identification. A sign may be a part of a logotype, but remain a separate unit, graphically, without using a print type of a name inscription, with the same characteristics as a logotype. In certain cases a sign is a single unit, it identifies a certain design object.

Such element of visual identification as a firm color set is one of key elements of a strong brand. Each color has its peculiarities, associations and psychological effect. Observing a color or color combinations, a recipient gets certain associations. Colors cause certain feelings and emotions, representing and indentifying a company, organization, creative group of another advertising object at the market. The same with a firm set of prints, used for identification and advertising. Depending on style of a chosen print, a recipient "reads" a hidden message by associations, despite a written sense. Text, accident, decorative or calligraphic prints, used at creating design objects for advertising, introduce own corrections in brand perception. The same is for business-structures and creative groups.

Not commonly, but often used visual identification elements for brand presentation are a corporative personage, form, cloth elements and other. Thus, a corporative personage stresses the main idea of a product and sets a connection between a client and a company. A personage is one of most interesting directions in video-advertising and polygraphic design, it is used on souvenir products; it can be seen on representative products and web-sites. It is also often used at conducting advertizing campaigns, both long-term and season ones. Personages become to be used more and 
more often for forming the image on an organization, they make advertizing campaigns brighter that is more effective.

It must be also noted, that such identification elements as a slogan and a sound are also often used in advertizing a product, although they are not visual, but have no less important influence together with visual identification elements. They have a great influence on brand formation and help promoting a product at the market, programming a recipient for certain expectations by associations.

All abovementioned visual identification elements are not a final list of components, used for brand representation. For example, the activity sphere of a company or creative group may add own specificity in visual identification elements' use. An activity sphere may add new senses to existing visual identification elements, create new visual images, combine elements, not permitted by a business-structure because of a company image or other corporative requirements.

For example, circus or theater creative groups have their own specificity in preparing to plays, creating images, fixed on them for a long time, may be visualized and put to the brand level (mask, first string, circus animal, instrument or environment). At the same time a concert activity of music groups or soloists also introduces certain corrections to visualization elements, allowing to identify them. The specificity of an activity sphere of creative groups, working in different culture fields, gives a possibility to separate additional visual identification elements, inherent to creative groups, regardless of their activity type. Thus, there may be considered additional visual identification elements, inherent only to creative groups, working in the sphere of music art.

Music performance style. A performance style may be also related to non-visual identification elements, but taking into account a whole series of visual images, inherent to a certain performance style, it is appropriately. There is rather opposite effect, - observing a visual object, for example, on a poster, a recipient understands in which style a creative group works. If a brake-dancer silhouette is on a poster, no one says that it is a concert of, for example, a symphony orchestra (obviously, if it is not an experimental show). Music theory distributes whole music in six main styles: classic, jazz, blues, pop, hip-hop, rock, and stable images exist for each one.

If consider functioning of a music brand in whole, an important and influent factor of its identification elements creation is just a music style, that a team works in. A music style has a great influence on image qualities of visual components; it determines a type of logotype inscription, color spectrum of advertising product, scenic cloth style, used accessories, merch and so on.

Rock is the most representative music style by identification elements in Ukraine. Mainly gothic prints with acute angles or destruction signs are used in logotypes of rock-groups. Black-white-red combinations with unessential amounts of other colors prevail in the color spectrum. If talk about the cloth culture, black color (leather and textile) dominates, jeans is a standard in separate rock-genres. Such visual set of elements for the rock style is not constant and unshakeable, but most often used.

The rock style is, in its turn, divided in several genres, each of which is remarkable for own visual identification elements that allow to relate a group to one or another genre. Thus, the music style of heavy rock genres is identified by such visual elements as make-up, combination of leather and metallic accessories, electric guitar, usually sounding on the distortion effect. For the folk and ethno genres - there are national identity elements or national music instruments. For the indie genre - there are acoustic instruments or ones, not typical for rocks music sound, or just made of improvised material, became a business card of such groups. For the punk and glam-rock genres there are freak artists' outlook transformations, bright images, rich make-up use. In their turn, progressive as far as techno are identified only by sounding, because just these two genres mainly use synthesized sounds, but visual images are a bit androgenic. This series may be continued by other rock-genres, but it is most important to understand that visual images, used for brand representation, must be comprehensive for a potential consumer. Identification of a music group with a certain performance style is an important factor for its authentication.

At the same time one more thing must be added: a genre of a music group can be defined by its name. For example, we can surely state, that such music groups as Motanka, Haydamaky, Kozak Systems, Coralli, Number 482, Khorta, Saber and many other are working in the Ukrainian folk genre, because their names contain a Ukrainian historical-cultural factor or ethic coloring, identifying their performance genre. 
A performance style is connected with another one element of music group identification music instruments. A performance style for many recipients it is a sound that is a set of certain instruments with an original manner of sound-making. Just a set of instruments is an important factor for indentifying a certain group, just this moment can be observed in such music art genres as folk, ethno, indie. Music instruments, used by musicians on scene, may become their business card. Instruments may be reflected in the name of a music group, in its logotype or signs, they may be a part of a created brand.

Among Ukrainian music groups from the studied list, we can mention a group Spiked kobzars, which name already informs about expectations of what can be heard at performances. Kobza is a national Ukrainian instrument, a kobzar historical figure is a symbol of the Ukrainian national spirit, perfectness in mastering this instrument is reflected in the work "spiked". Thus, the music group disposes a recipient on the folk or ethnic music genre, identifies itself by the name, creating a certain moment of the brand.

There can be also listed a Kyiv instrumental duet "B\&B project", which doesn't have a distinct logotype of the group that is a verbal inscription of the name, but has a sign of two music instruments - bandura and bayan. These two instruments begin from the letter " $b$ " that just gives the name of the project (written in the Roman alphabet). The duet makes high-quality cover-versions of music compositions just by bandura and bayan that became their business card, distinct identification element.

The name of a music group "Boom box" is also a reflection of a certain expectation from their work. A logotype, used by the group, reflects the graphic interpretation of a type of an audio-apparatus boom box against the background of the wide list of music instruments and devices and a five-pointed star. The list of music instruments and devices, marked on the sign (microphone, guitars, loud speakers, record-player) is a set of instruments for disc jockey's work and club music reproduction. These signs became a business card of the music group, main element of graphic identification that reflected the brand of the group - its perception by recipients.

Cloth and accessories must be considered as an additional visual identification element. Design theory relates cloth to commonly used visual identification elements; it is mainly about a corporative style or corporative culture, but not all cloth elements can be related to commonly used ones, because some of them cannot be used, for example, in business-structures or educational institutions, because their culture and image don't allow this.

As to cloth additional visual identification elements, we can talk about epatage or freak subculture. Freak it is a person, remarkable for bright, non-standard outlook or strange manners. Such people most often attract attention by original hairstyles, specific cloth and non-standard manner of wearing it. Today freaks are a spread trend among youth, at the same time a non-standard outlook may be observed in creative people, besides it doesn't mean what art sphere a person works in, its main aim is to be remarkable.

Among Ukrainian scene musicians there are many performers, related to some extend to the freak subculture, for example, the group Vopli Vidopliassova, "Onuka", "The Hardkiss", "Vivienne Mort", "Dakha Brakha", "Dzidzio" and Drymba Da Dzyga, and several groups certainly pose themselves just as freaks, for example, the freak-cabaret "Dakh Daughters Band". The main idea of the brand work is to be notable among other same people, working in the same sphere of business, art and even in the same genre, and the freak outlook and epatage reliably favor it.

Branding of music groups and reflection of their identifiers are influenced by many factors, difficultly connected with business concreteness, inherent to most business-structures. Among such factors, influencing a type of music group identifiers, we can name make-up that is creation of a non-standard individual grease paint. This principle was used by members of the famous American group Kiss (New York) and many other performers. Some of them made it for hiding own personality, other ones - for being notable among others by a non-standard outlook. Among examples we can list such names as David Bowie (British performer David Robert Jones), Conchita Wurst (Austrian performer Thomas Neuwirth), Marilyn Manson (American musician Brian Hugh Warner).

At the Ukrainian scene there are many performers, who use excessive make-up and grease paint for their scenic image. Among them we can name the music group "Panivalkova", whose 
performances are very bright. Each show of this group is accompanied by a dramatized event with using bright attributes, accessories and make-up.

Other additional identifiers of music groups may be also found, but they are rather exclusions than determined approaches to their creation that may be formed in a certain structure or classified by some signs.

For example, the music group "From the screw" reliably uses almost whole list of both common and additional visual identification elements. It has its logotype, firm color and print sets, corporative personages, sets of music instruments that are reflected in personages and give an answer about a performance style, the corporative cloth and epatage outlook of performers are also used. And it is not a single example in the Ukrainian music space.

\section{Discussion}

The study is based on requirements of the modern Ukrainian education and analysis of data of future specialists' training in the design sphere as to their professional competence formation. The obtained research results testify to the necessity to renovate the theoretical base in the sphere of visual identification studying. The specificity of any activity sphere needs introducing certain corrections to the existent commonly accepted theory. Just that is why it is reasonable to consider certain human activity spheres as demonstrative to reveal visual identification elements that may be added to commonly used ones.

This research is based on the obtained results and experience of foreign specialists, who have already studied the theme of visual identification in brand formation. The review of sources demonstrates that the main part of all materials, dedicated to this topic, mostly deals with methods of visual identification elements creation, considering logotype as one of main elements, often ignoring no less important specific ones. The modern interpretation of design theory about logotype, identification and brand is offered by a series of internet-resources of leading designers and design agencies. Brand as a separate phenomenon is opposed to its elements [10, 11] or general notions, confirming scientific theories are given [12-14], that testifies to the more or less formed theory about commonly used visual identification elements. At the same time scientific editions in the sphere of design talk about brand as a complete visual presentation and unified image [15], describing an identity as "distillation" of a visual style [16] and giving the own definition to the notion "brand" [17]. It doesn't deny this research, but gives a possibility for further study of this topic, based on the specificity of creative audiovisual activity spheres, namely, music art.

Prospects of further studies may be modern digital technologies, introducing new symbols and signs in identification elements visualization, and it, in its turn, needs revision of the list of visual identification elements that transfers to the status of motion-design.

\section{Conclusions}

Music art introduces own corrections in design theory as to the list of visual identification elements, because it is influenced by several factors, not inherent to business structures and social associations.

Each art type may also introduce own additional elements in the list of visual identification elements, if interactive communication with recipients for creating own brand is needed.

A list of visual identification elements may contain common ones, used by all social structures and additional elements, inherent to a separate sector of activity or art only.

For highlighting themselves in a series of groups, working in the same activity sector, music groups use such visual identification elements as:

- music performance style, influencing figurative graphic elements;

- music instruments that may be part of a graphic image;

- freak outlook that is a visual element of performers' style;

- make-up that is a visual element of performers' style.

This list of additional visual identification elements of music groups is not complete and may be added by other elements. 


\section{References}

[1] Morgan, G. (2005). Images of Organization. California: Thousand Oaks, 416.

[2] Barden, Ph. (2013). Decoded: the science behind why we buy. New York: John Wiley \& Sons, Inc., 288. doi: http://doi.org/ $10.1002 / 9781119208341$

[3] Berman, M. (2010). Street-smart Advertising: How to Win the Battle of the Buzz. Lanham: Rowman \& Littlefield Publishers, 352 .

[4] Neumeier, M. (2007). ZAG: the \# 1 strategy of high-performance brands. New-York: AIGA, 192.

[5] Ogilvy, D. (1985). Ogilvy on Advertising. New York: Random House, 224.

[6] Norman, D. (2013). The Design of Everyday Things. New York: Basic Books, 268.

[7] Bezsonova, L. (2011). Morfolohiia lohotypu v systemi identyfikatsiinoi znakovoi hrafiky. Visnyk KhDADM, 3, 4-7.

[8] Poliak, R. (2013). Elementy sproshchenoi systemy vizualnoi identyfikatsii v malykh i serednikh pidpryiemstvakh. Visnyk Lvivskoho universytetu. Seriia zhurnalistyka, 37, 190-199.

[9] Heller, S., Chwast, S. (2011). Graphic Style from Victorian to New Century. New-York: Abrams, 320.

[10] What is the difference between a logo, identity and brand? (2014). Stone Soup Creative. Available at: https://www.stonesoupcreative.com/difference-logo-identity-brand/

[11] Halstead J. (2012) Brand vs. Logo: The Mystery Solved. Available at: https://gistbrands.net/brand-vs-logo/

[12] The importance of a Brand Identity System. Spellbrand. Available at: https://www.spellbrand.com/

[13] How to Create a Powerful Brand. Stidioldesign. Available at: https://studioldesign.com/how-to-create-a-powerful-brandidentity/

[14] Herndon, M. (2016). How to Design a Brand Identity System That Works for Your Clients. Available at: https://milesherndon. com/blog/design-brand-identity-system

[15] Fu, X. F. (2011). The Design of VIS for Henan Institute of Engineering. Advanced Materials Research, 211-212, 788-792. doi: http://doi.org/10.4028/www.scientific.net/amr.211-212.788

[16] Balmer, J. M. T. (2010). Explicating corporate brands and their management: Reflections and directions from 1995. Journal of Brand Management, 18 (3), 180-196. doi: http://doi.org/10.1057/bm.2010.46

[17] Baumgarth, C. (2010). "Living the brand": brand orientation in the business-to-business sector. European Journal of Marketing, 44 (5), 653-671. doi: http://doi.org/10.1108/03090561011032315 